\title{
Stroke doctors : Who are we? A World Stroke Organization survey
}

\section{Meretoja, Atte}

2017-10

Meretoja , A , Acciarresi , M , Akinyemi , R O , Campbell , B , Dowlatshahi , D , English , C , Henninger , N , Poppe , A , Putaala , J , Saini , M , Sato , S , Wu , B , Brainin , M , Norrving , B \& Davis , S 2017 , ' Stroke doctors : Who are we? A World Stroke Organization survey ' , International Journal of Stroke , vol. 12 , no. 8 , pp. 858-868 . https://doi.org/10.1177/1747493017701150

http://hdl.handle.net/10138/298045

https://doi.org/10.1177/1747493017701150

publishedVersion

Downloaded from Helda, University of Helsinki institutional repository.

This is an electronic reprint of the original article.

This reprint may differ from the original in pagination and typographic detail.

Please cite the original version. 


\section{Stroke doctors: Who are we? A World Stroke Organization survey}

\author{
Atte Meretoja ${ }^{1,2,3}$, Monica Acciarresi ${ }^{4}$, Rufus O Akinyemi ${ }^{5}$, \\ Bruce Campbell', Dar Dowlatshahi ${ }^{6}$, Coralie English ${ }^{7}$, \\ Nils Henninger 8,9 , Alexandre Poppe ${ }^{10}$, Jukka Putaala ${ }^{3}$, \\ Monica Saini $^{11,12}$, Shoichiro Sato ${ }^{13,14}$, Bo Wu ${ }^{15}$, Michael Brainin ${ }^{16}$, \\ Bo Norrving ${ }^{17}$ and Stephen Davis'
}

International Journal of Stroke 2017, Vol. 12(8) 858-868 (C) 2017 World Stroke Organization Reprints and permissions: sagepub.co.uk/journalsPermissions.nav DOI: $10.1177 / 1747493017701150$ journals.sagepub.com/home/wso @SAGE

\begin{abstract}
Background: Specialist training provides skilled workforce for service delivery. Stroke medicine has evolved rapidly in the past years. No prior information exists on background or training of stroke doctors globally.
\end{abstract}

Aims: To describe the specialties that represent stroke doctors, their training requirements, and the scientific organizations ensuring continuous medical education.

Methods: The World Stroke Organization conducted an expert survey between June and November 2014 using emailed questionnaires. All Organization for Economic Co-operation and Development countries with $>$ I million population and other countries with $>50$ million population were included $(n=49$, total 5.6 billion inhabitants, $85 \%$ of global strokes). Two stroke experts from each selected country were surveyed, discrepancies resolved, and further information on identified stroke-specific curricula sought.

Results: We received responses from 48 (98\%) countries. Of ischemic stroke patients, 64\% were reportedly treated by neurologists, ranging from $5 \%$ in Ireland to $95 \%$ in the Netherlands. Per thousand annual strokes there were average six neurologists, ranging from 0.3 in Ethiopia to 33 in Israel. Of intracerebral hemorrhage patients, $29 \%$ were reportedly treated by neurosurgeons, ranging from $5 \%$ in Sweden to $79 \%$ in Japan, with three neurosurgeons per thousand strokes, ranging from 0.1 in Ethiopia to 24 in South Korea. Most countries had a stroke society (86\%) while only 10 (21\%) had a degree or subspecialty for stroke medicine.

Conclusions: Stroke doctor numbers, background specialties, and opportunities to specialize in stroke vary across the globe. Most countries have a scientific society to pursue advancement of stroke medicine, but few have stroke curricula.

\footnotetext{
'Department of Medicine, Royal Melbourne Hospital, University of Melbourne, Parkville, VIC, Australia

${ }^{2}$ The Florey Institute of Neuroscience and Mental Health, Parkville, VIC, Australia

${ }^{3}$ Department of Neurology, Helsinki University Hospital, Helsinki, Finland ${ }^{4}$ Stroke Unit and Division of Cardiovascular Medicine, Ospedale Santa Maria della Misericordia, University of Perugia, Perugia, Italy

${ }^{5}$ Neurosciences and Ageing Research Unit, Institute for Advanced Medical Research and Training, College of Medicine, University of Ibadan, Ibadan, Nigeria

${ }^{6}$ Department of Medicine (Neurology), Ottawa Hospital Research Institute, University of Ottawa, Ottawa, ON, Canada

${ }^{7}$ School of Health Sciences and Priority Research Centre for Stroke and Brain Injury, University of Newcastle, Newcastle, NSW, Australia

${ }^{8}$ Department of Neurology, University of Massachusetts Medical School, Worcester, MA, USA

${ }^{9}$ Department of Psychiatry, University of Massachusetts Medical School, Worcester, MA, USA

${ }^{10}$ Department of Medicine (Neurology), Hôpital Notre-Dame, University of Montreal, Montreal, QC, Canada
}

\footnotetext{
"Department of Medicine, Changi General Hospital, Singapore, Singapore

${ }^{12}$ Memory Ageing and Cognition Centre, National University of Singapore, Singapore, Singapore

${ }^{13}$ Department of Cerebrovascular Medicine, National Cerebral and Cardiovascular Center, Osaka, Japan

${ }^{14}$ Neurological and Mental Health Division, The George Institute for Global Health, Sydney, NSW, Australia

${ }^{15}$ Department of Neurology, West China Hospital, Sichuan University, Chengdu, China

${ }^{16}$ Center of Clinical Neurosciences, Danube University of Krems, Krems, Austria

${ }^{17}$ Department of Clinical Sciences Lund, Neurology, Lund University, Lund, Sweden and Department of Neurology and Rehabilitation Medicine, Skåne University Hospital, Lund, Sweden
}

Corresponding author:

Atte Meretoja, Helsinki University Hospital, PO Box 220, Helsinki 00029 , Finland.

Email: atte.meretoja@fimnet.fi 


\section{Keywords}

Stroke, education, training, curriculum, specialist, workforce, organization, college

Received: 16 August 2016; accepted: 27 November 2016

\section{Introduction}

Given the overall worldwide body of knowledge in medicine increases constantly and at an accelerating rate, it is not possible to fully master the entire spectrum. Therefore, most doctors engage in specialist and subspecialty training. Further, continuous medical education, mostly provided by scientific specialist organizations, is necessary to maintain reasonable standards of practice. However, the way doctors are trained and healthcare services are delivered vary from country to country.

Over a period of a few decades, the treatment of stroke patients has transformed from passive observation on general medical wards to active, specialized care, rich in protocols and procedures. Stroke units and revascularization therapies have been the most practice-changing advances. These and various other new techniques such as carotid endarterectomy, stroke intensive care, and neurosurgical interventions require highly skilled personnel. ${ }^{1,2}$ As a consequence, a subspecialty of "strokologists" has emerged in clinical practice, ${ }^{3}$ but educational systems have often not formalized this development. Changes in stroke medicine will have profound effects on workforce demand in the future. ${ }^{4}$ Currently, stroke patients are being cared for by various specialists in different settings, including neurologists, neurosurgeons, geriatricians, emergency doctors, rehabilitation specialists, and general physicians. No comprehensive data exist on global practices of educating stroke doctors.

The aim of this study was to answer three questions: Which specialties do doctors treating stroke patients represent? How are they being trained? Do they have scientific organizations to ensure quality in continuous medical education?

\section{Methods}

The study was endorsed and co-ordinated by the Young Stroke Professionals Committee of the World Stroke Organization (WSO), the global scientific organization for stroke medicine.

We performed an expert survey using short e-mailed questionnaires (Online Panel A). Two stroke experts from each selected country, at different stages of their career, and different institutes were approached and invited to participate. The respondents were primarily identified among WSO members, and if not available, through national stroke organizations, or stroke- related publications. An e-mail questionnaire accompanied by a letter of invitation was sent, followed by two reminders as needed. If no replies were received, another person from the same country was approached. The responses of the two experts from each country were compared. Any discrepancies were clarified with the experts and checked against further sources. Further descriptions of existing stroke-specific curricula were sought from the identified curriculum contacts.

We limited the scope of our study to countries which were Organisation for Economic Co-operation and Development (OECD) members with $>1$ million population or non-OECD countries with a population of $>50$ million.

\section{Results}

We received responses from all countries except Bangladesh, with a response rate of $98 \%$ of the countries selected. For Bangladesh, we used publicly available data on numbers of doctors. The 49 countries included represent $78 \%$ of world population, $85 \%$ of world strokes, and $>95 \%$ of global stroke research output. ${ }^{5}$

With a few exceptions, ${ }^{6-11}$ the experts did not identify published articles on the number of stroke patients treated by different specialties. Therefore, the country estimates of stroke doctor specialties are mainly based on expert opinion. In most countries, stroke patients were treated by neurologists. In some, mostly Commonwealth countries, general medicine was the main treating specialty. Treatment of intracerebral hemorrhage varied by country between neurology, general medicine, and neurosurgery (Figure 1). The numbers of neurologists and neurosurgeons per population differed widely by country (Table 1 and Figure 2). Also the content and duration of specialist training in neurology and neurosurgery varied across countries, being typically five years in duration, but ranging from two to seven (Online Table 1).

Ten of the included countries had a specialty, subspecialty, or similar national degree in stroke medicine. Additionally, the European Stroke Organisation has a training program in collaboration with the Donau University Krems in Austria. The duration of the stroke programs ranged from nine months to three years (Table 2). Further information on the programs is available via links in Online Panel B.

All but seven of the countries had a national stroke society. Many, but not all of these societies were 
Figure I. Proportion of ischemic stroke (left panel) and intracerebral hemorrhage (right panel) patients by treating specialty. Data are based on expert opinion with the exception of Belgium, Finland, Hungary, India, Japan, and the United States which have published data. ${ }^{6-11}$

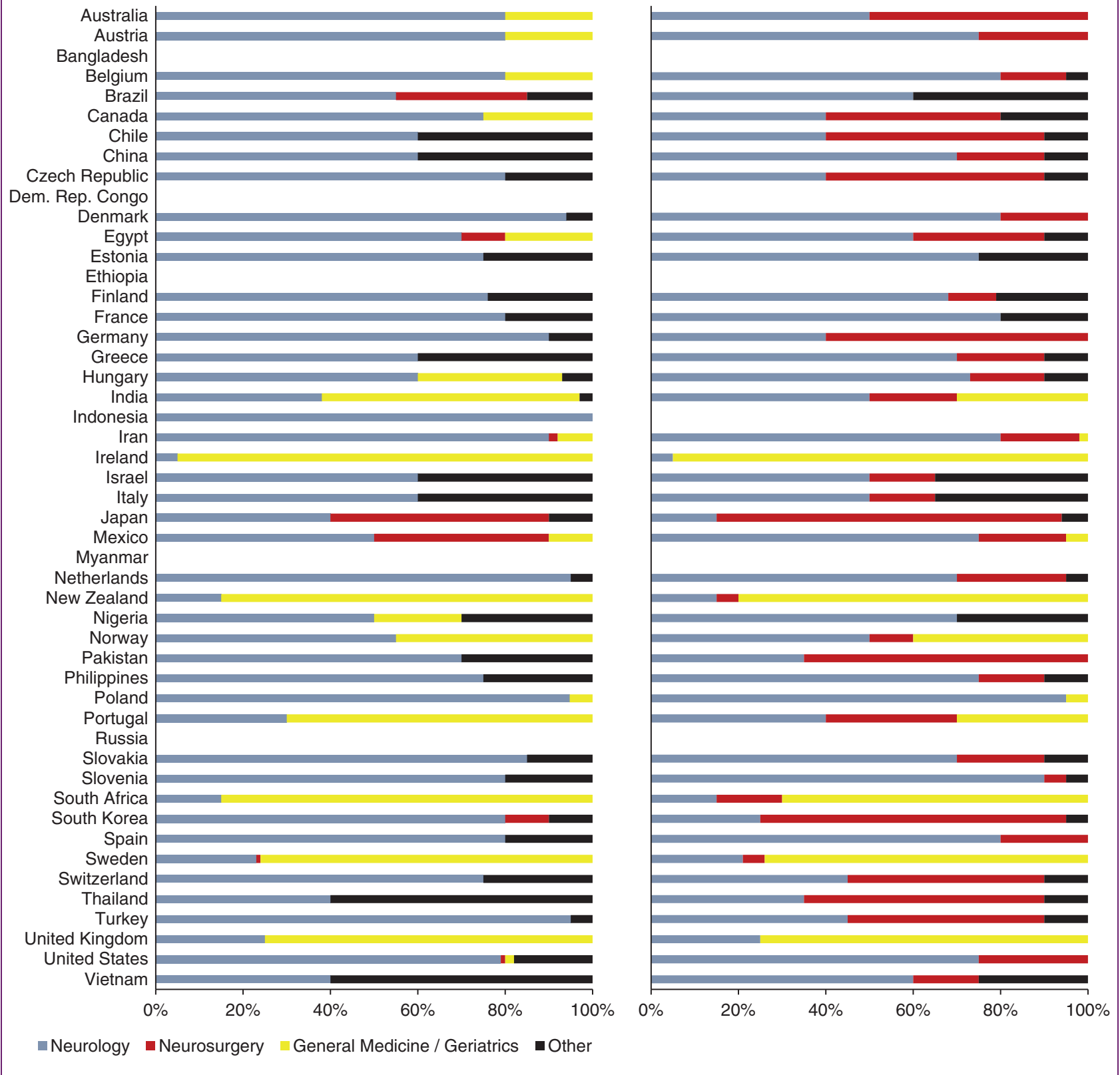

member organizations of the WSO. The highest WSO member rates per population were from Australia (Table 3).

\section{Discussion}

As health service delivery in the field of stroke is rapidly evolving, and in light of the increasing stroke incidence due to an aging world population, stroke specialist training faces distinct challenges. In this survey, we, for the first time, summarized the specialist background, current curricula, and national scientific societies in stroke medicine. While the main specialty responsible for stroke in most countries was identified as neurology, many countries are an exception to this rule, and the main treating specialty of intracerebral hemorrhage varied widely. Stroke societies exist in almost every country, but stroke curricula are less common. These existing stroke programs can be utilized as a framework by countries and organizations 
Table I. Population, stroke incidence, and the numbers of neurologists and neurosurgeons.

\begin{tabular}{|c|c|c|c|c|c|}
\hline Country & $\begin{array}{l}\text { Population } \\
\text { (millions) }\end{array}$ & $\begin{array}{l}\text { Ischemic } \\
\text { strokes }^{\text {a }}\end{array}$ & $\begin{array}{l}\text { Hemorrhagic } \\
\text { strokes }^{\mathrm{a}}\end{array}$ & Neurologists & Neurosurgeons \\
\hline Australia & 22.3 & 30 & 9 & 456 & 120 \\
\hline Austria & 8.3 & 19 & 6 & 582 & 100 \\
\hline Bangladesh & 152.5 & 96 & 49 & 110 & 113 \\
\hline Belgium & 10.9 & 25 & 7 & 530 & 180 \\
\hline Brazil & 193.3 & 313 & 116 & 5000 & 3500 \\
\hline Canada & 34.1 & 67 & 16 & 881 & 306 \\
\hline Chile & 17.1 & 15 & 9 & 244 & 114 \\
\hline China & $134 \mid .3$ & 3308 & 2305 & 15,000 & 6000 \\
\hline Czech Republic & 10.5 & 43 & 10 & 1100 & 85 \\
\hline Dem. Rep. of the Congo & 67.5 & 37 & 20 & 49 & 4 \\
\hline Denmark & 5.5 & 14 & 5 & 237 & 110 \\
\hline Egypt & 86.2 & 72 & 25 & 500 & 700 \\
\hline Estonia & 1.3 & 13 & 2 & 110 & 15 \\
\hline Ethiopia & 86.6 & 50 & 34 & 26 & 10 \\
\hline Finland & 5.4 & 21 & 7 & 323 & 65 \\
\hline France & 63.0 & 119 & 40 & 2100 & 450 \\
\hline Germany & 81.8 & 285 & 86 & 4238 & 1464 \\
\hline Greece & 11.3 & 25 & 8 & 832 & 200 \\
\hline Hungary & 10.0 & 55 & 12 & 867 & 108 \\
\hline India & 1224.6 & 1098 & 472 & 1100 & 1500 \\
\hline Indonesia & 239.9 & 245 & 195 & 1200 & 240 \\
\hline Iran & 77.3 & 288 & 63 & 700 & 500 \\
\hline Ireland & 4.5 & 7 & 2 & 61 & 28 \\
\hline Israel & 7.6 & 10 & 3 & 432 & 56 \\
\hline Italy & 60.5 & 111 & 33 & 3000 & 720 \\
\hline Japan & 128.1 & 458 & 180 & 5122 & 7207 \\
\hline Mexico & 108.4 & 89 & 35 & || $4 \mid$ & 956 \\
\hline Myanmar & 56.2 & 49 & 38 & 22 & 13 \\
\hline Netherlands & 16.6 & 27 & 9 & 845 & 130 \\
\hline New Zealand & 4.4 & 6 & 2 & 40 & 21 \\
\hline
\end{tabular}


Table I. Continued

\begin{tabular}{|c|c|c|c|c|c|}
\hline Country & $\begin{array}{l}\text { Population } \\
\text { (millions) }\end{array}$ & $\begin{array}{l}\text { Ischemic } \\
\text { strokes }^{\text {a }}\end{array}$ & $\begin{array}{l}\text { Hemorrhagic } \\
\text { strokes }^{\mathrm{a}}\end{array}$ & Neurologists & Neurosurgeons \\
\hline Nigeria & 173.6 & 96 & 57 & 80 & 25 \\
\hline Norway & 4.9 & 10 & 3 & 324 & 70 \\
\hline Pakistan & 186.0 & 114 & 54 & 120 & 150 \\
\hline Philippines & 99.3 & 73 & 44 & 270 & 52 \\
\hline Poland & 38.2 & 116 & 32 & 3000 & 400 \\
\hline Portugal & 10.6 & 27 & 11 & 314 & 140 \\
\hline Russia & 142.5 & 847 & 124 & 8000 & 2900 \\
\hline Slovakia & 5.4 & 18 & 4 & 700 & 75 \\
\hline Slovenia & 2.0 & 8 & 2 & 143 & 20 \\
\hline South Africa & 56.0 & 49 & 30 & 155 & 182 \\
\hline South Korea & 49.4 & 77 & 36 & 1920 & 2740 \\
\hline Spain & 46.1 & 102 & 32 & 1607 & 442 \\
\hline Sweden & 9.4 & 27 & 7 & 316 & 120 \\
\hline Switzerland & 7.8 & 17 & 5 & 546 & 169 \\
\hline Thailand & 65.9 & 114 & 67 & 750 & 350 \\
\hline Turkey & 72.7 & 75 & 26 & 1725 & 1500 \\
\hline United Kingdom & 61.3 & 112 & 34 & 694 & 265 \\
\hline United States & 309.3 & 755 & 188 & 16,366 & 3500 \\
\hline Vietnam & 89.7 & 94 & 85 & 400 & 250 \\
\hline Total in the study & 5567 & 9726 & 4638 & 84,278 & 38,478 \\
\hline Non-study countries & 1585 (22\%) & 1844 (16\%) & 687 (13\%) & & \\
\hline
\end{tabular}

${ }^{a}$ Incidence in thousands in the year 2010 according to the Global Burden of Disease Study. ${ }^{12}$

that plan to develop a new, or revise an existing, stroke training curriculum.

Notably, in many countries, the main treating specialty for stroke is internal/general/geriatric medicine. Although risk factors for stroke and acute complications fall largely in the field of these specialties, the differential diagnosis and long-term complications are neurological. Therefore, neurologists well trained in general medicine may be best suited to treat stroke patients.

Specialist training in medicine and neurology is rapidly changing, with a trend towards subspecialization. ${ }^{13}$ In the English literature, a subspecialty in stroke was first suggested in 1997, ${ }^{14}$ and then established in 2003 in the USA ${ }^{15}$ and in 2004 in the UK. ${ }^{16}$ Later, subspecialty training in neurovascular interventions ${ }^{17}$ and neurocritical care ${ }^{18}$ has been set up in the USA. Even working fulltime in a hospital, the so-called neurohospitalist has been suggested to be a specialized group of neurologists. ${ }^{19}$ A policy paper on what European young neurologists considered important in stroke training has been published $^{20}$ but has received little attention since. Despite harmonization of higher education in Europe through the Bologna process, the education and healthcare systems still differ widely within the continent. Basic medical degrees are mostly not involved in this European unification, and specialist training not at all. To our knowledge, no other attempts exist for 
Figure 2. Number of neurologists and neurosurgeons per 1000 annual incident stroke patients.

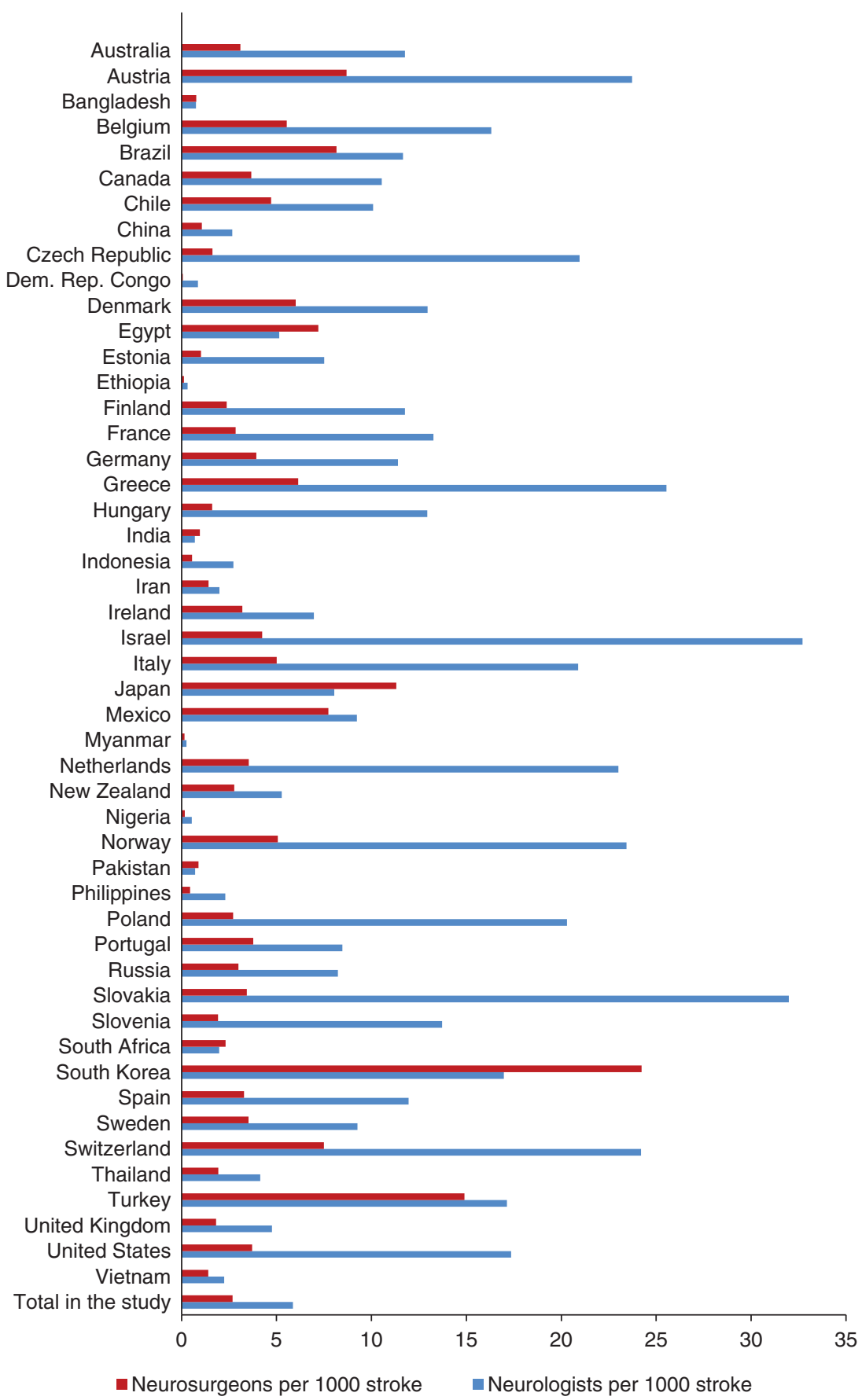

harmonizing medical education internationally. The data published here provide new insights into how stroke is being taught globally and may serve to help build collaborations between different systems and thus converge education in the future.

A recent literature review of medical education in the field of neurology failed to identify any articles comparing specialist training programs in neurology or stroke. ${ }^{21}$ There is very little data on stroke education overall. In 1992, primary care physicians' and second year medical students' knowledge on stroke was studied in Minnesota, USA, finding disturbing knowledge gaps in both groups. ${ }^{22}$ In 1995, a report on undergraduate and postgraduate training in cerebrovascular disease, 


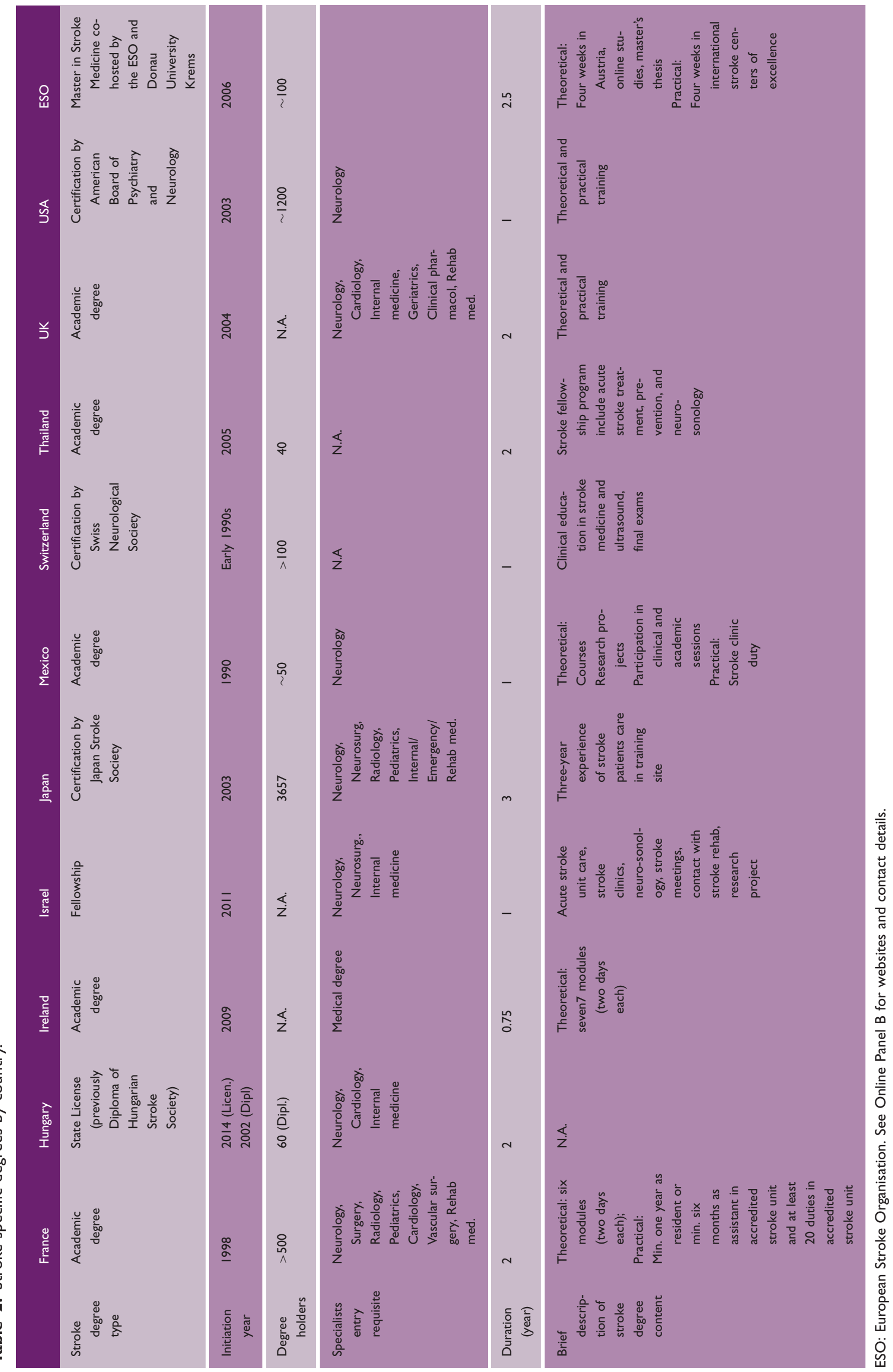


Table 3. Scientific stroke societies and World Stroke Organization (WSO) membership by country.

\begin{tabular}{|c|c|c|c|c|}
\hline Country & $\begin{array}{l}\text { National } \\
\text { scientific } \\
\text { stroke society }\end{array}$ & $\begin{array}{l}\text { WSO organizational } \\
\text { members } \\
\text { scientific/support }\end{array}$ & $\begin{array}{l}\text { WSO } \\
\text { individual } \\
\text { members }\end{array}$ & $\begin{array}{l}\text { WSO individual } \\
\text { members per } \\
10 \text { million population }\end{array}$ \\
\hline Australia & + & $\mathrm{I} / \mathrm{I}$ & 215 & 96 \\
\hline Austria & + & & 14 & 17 \\
\hline Bangladesh & + & I/- & 3 & 0.2 \\
\hline Belgium & + & $\mathrm{I} /-$ & 11 & 10 \\
\hline Brazil & + & $2 / 1$ & 38 & 2 \\
\hline Canada & + & $2 / 1$ & 65 & 19 \\
\hline Chile & No & & 6 & 4 \\
\hline China & + & $1 /-$ & 806 & 6 \\
\hline Czech Republic & + & & 6 & 6 \\
\hline Dem. Rep. of the Congo & No & & I & \\
\hline Denmark & + & $1 /-$ & 3 & 5 \\
\hline Egypt & + & & 56 & 6 \\
\hline Estonia & + & & 0 & \\
\hline Ethiopia & No & & 0 & \\
\hline Finland & + & $1 / 1$ & 16 & 30 \\
\hline France & + & I/- & 13 & 2 \\
\hline Germany & + & I/- & 45 & 6 \\
\hline Greece & + & $1 /-$ & 5 & 4 \\
\hline Hungary & + & & 2 & 2 \\
\hline India & + & -12 & 50 & 0.4 \\
\hline Indonesia & + & $1 /-$ & 16 & I \\
\hline Iran & No & $2 /-$ & 105 & 14 \\
\hline Ireland & + & & II & 24 \\
\hline Israel & No & -11 & 5 & 7 \\
\hline Italy & + & & 22 & 4 \\
\hline Japan & + & $2 /-$ & 100 & 8 \\
\hline Mexico & + & & 7 & I \\
\hline Myanmar & No & & 5 & I \\
\hline Netherlands & + & & 13 & 8 \\
\hline
\end{tabular}


Table 3. Continued

\begin{tabular}{|c|c|c|c|c|}
\hline Country & $\begin{array}{l}\text { National } \\
\text { scientific } \\
\text { stroke society }\end{array}$ & $\begin{array}{l}\text { WSO organizational } \\
\text { members } \\
\text { scientific/support }\end{array}$ & $\begin{array}{l}\text { WSO } \\
\text { individual } \\
\text { members }\end{array}$ & $\begin{array}{l}\text { WSO individual } \\
\text { members per } \\
10 \text { million population }\end{array}$ \\
\hline New Zealand & + & -11 & 23 & 52 \\
\hline Nigeria & + & $\mathrm{I} / \mathrm{I}$ & 17 & I \\
\hline Norway & + & & 9 & 18 \\
\hline Pakistan & + & $1 /-$ & 4 & 0.2 \\
\hline Philippines & + & $1 /-$ & 10 & 1 \\
\hline Poland & + & $\mathrm{I} / \mathrm{-}$ & 5 & I \\
\hline Portugal & + & $1 /-$ & 7 & 7 \\
\hline Russia & + & & 5 & 0.4 \\
\hline Slovakia & + & & I & 2 \\
\hline Slovenia & + & & I & 5 \\
\hline South Africa & + & $0 / 2$ & 1 & 0.2 \\
\hline South Korea & + & $1 /-$ & 57 & 12 \\
\hline Spain & + & $\mathrm{I} / \mathrm{-}$ & 19 & 4 \\
\hline Sweden & No & & 10 & 11 \\
\hline Switzerland & + & $1 / 1$ & 19 & 24 \\
\hline Thailand & + & $1 /-$ & 46 & 7 \\
\hline Turkey & + & $1 /-$ & 9 & 1 \\
\hline United Kingdom & + & $2 / 2$ & 66 & 11 \\
\hline United States & + & $2 / 3$ & 99 & 3 \\
\hline Vietnam & + & & 7 & I \\
\hline Total in the study & & $32 / 17$ & 2054 & 4 \\
\hline Excluded countries & & $7 / 3$ & 127 & \\
\hline
\end{tabular}

based on a survey of 40 centers in USA and Canada, concluded that stroke was hardly being taught at all during the course of basic medical training or specialist training in internal medicine. ${ }^{23}$ When stroke components have been introduced to basic medical training, retained learning and student satisfaction were demonstrated in a study at the University of Massachusetts. ${ }^{24}$ Neurology specialist curricula and training practices have been evaluated on national level in Finland, but only published in Finnish. ${ }^{25}$ It is quite possible that there are many other national and nationally published studies on specialist training which we were not able to identify. As specialist medical training in general serves national demand, details are often not available in English or published in the international literature. We were positively surprised to learn of the 11 existing curricula described in Table 2 and Online Panel B. For most countries, the language barrier prevents gaining detailed data on their national specialist training programs based on publicly available materials alone. Such data are crucial for planning of new curricula, revision of existing curricula, any attempts at harmonization, and to inform policies around international mobility of clinicians.

We observed marked differences in the numbers of neurologists and neurosurgeons by country (Figure 2). 
All the 10 countries with $>20$ neurologists $/ 1000$ stroke cases per year were in Europe, while some European countries such as Sweden, UK, and Ireland had substantially fewer-these were the same countries where stroke was less often treated by neurologists. Similarly, there were more neurosurgeons than neurologists in Japan and South Korea, the countries where a significant number of stroke patients were treated by neurosurgeons. Our data provide no answer as to whether the observed differences in treatment practices are a consequence of the available workforce or vice versa. Overall resource of neurologists and neurosurgeon were low in low- and middle-income countries (Figure 2). A possible effective strategy for these countries may be the engagement of their nationals in diaspora in highincome nations who have acquired high levels of skills in stroke medicine to use their expertise and experiences to help build effective systems in their home nations. ${ }^{26}$

Our survey was limited to only two responses per country. We sought national experts to help identify existing literature on specialties treating stroke patients. Very little published data were identified, and therefore, most of the estimates are based on expert opinion only. These opinions represent only limited geographic locations and select, more often academic, institutions. It is also possible the national experts missed some existing published data. Therefore, our estimates may not be accurate and probably overestimate specialist involvement in stroke care overall. This underlines the need to collect and publish more high-quality data on medical specialists treating stroke patients which can be used for planning the basic and continuous education of these doctors. Also, the interesting finding of how care of stroke patients is divided equally between neurologists and neurosurgeons in many countries suggests a more collaborative approach might be warranted in medical education, and at scientific society level between these specialties. Finally, our survey was performed in 2014 prior to the publication of the positive endovascular clot retrieval trials. For this reason, we did not collect data on training of interventional neuroradiology. This is an important topic and should be included in future updates of our survey.

To conclude, stroke medicine is practiced by doctors of various training background in different countries of which few have specific training programs for stroke. Still, most do have a scientific society, the first requirement to start evolving such curricula. In many countries, stroke patients are not treated by doctors specialized in stroke medicine, but rather by generalists. Treatment of stroke patients by specialists has been associated with better conformance with guidelines, shorter hospital stays, and improved patient outcomes. ${ }^{6,27,28}$ Thus, an efficient training system providing stroke specialists would likely have direct benefit on patient outcomes. It would serve stroke patients well to have more stroke specialists taking care of them. No comprehensive data have previously been compiled on the variance of different national practices of educating and scientifically organizing stroke specialists. We hope our data serve to inspire developments in countries where such systems are yet to be implemented, and to promote interaction between existing national organizations.

\section{Acknowledgments}

We thank all the numerous national experts who offered their time and expertise allowing us to collate this report.

\section{Authors' contributions}

AM conceived and co-ordinated the project and drafted the manuscript. All authors collected data, interpreted the data, and edited the manuscript for intellectual contribution.

\section{Declaration of conflicting interests}

The author(s) declared the following potential conflicts of interest with respect to the research, authorship, and/or publication of this article: All authors are members of the WSO Young Stroke Professionals Committee and/or the Board. WSO is the global body for advancement of stroke medicine. Prof Brainin is the head of the Master in Stroke Medicine training program at the Donau University Krems.

\section{Funding}

The author(s) disclosed receipt of the following financial support for the research, authorship, and/or publication of this article: Dr Henninger is supported by K08NS091499 from the National Institute of Neurological Disorders and Stroke.

\section{References}

1. Jauch EC, Saver JL, Adams HP Jr, et al. Guidelines for the early management of patients with acute ischemic stroke: a guideline for healthcare professionals from the American Heart Association/American Stroke Association. Stroke 2013; 44: 870-947.

2. Steiner T, Al-Shahi Salman R, Beer R, et al. European Stroke Organisation (ESO) guidelines for the management of spontaneous intracerebral hemorrhage. Int $J$ Stroke 2014; 9: 840-855.

3. Donnan GA and Davis SM. Neurologist, internist, or strokologist? Stroke 2003; 34: 2765.

4. Zipfel GJ, Derdeyn CP and Dacey RG Jr.. Current status of manpower needs for management of cerebrovascular disease. Neurosurgery 2006; 59: S261-S270; discussion S263-S213.

5. Asplund K, Eriksson M and Persson O. Country comparisons of human stroke research since 2001: a bibliometric study. Stroke 2012; 43: 830-837.

6. Meretoja A, Kaste M, Roine RO, et al. Trends in treatment and outcome of stroke patients in Finland from 1999 to 2007. PERFECT Stroke, a nationwide register study. Ann Med 2011; 43: S22-S30. 
7. Thijs V, Peeters A, Dewindt A, et al. Organisation of inhospital acute stroke care and minimum criteria for stroke care units. Recommendations of the Belgian Stroke Council. Acta Neurol Belg 2009; 109: 247-251.

8. Toyoda K. [Contribution of neurologists to emergent stroke medicine in Japan]. Rinsho Shinkeigaku 2013; 53: 1370-1372.

9. Pandian JD, Kalra G, Jaison A, et al. Knowledge of stroke among stroke patients and their relatives in Northwest India. Neurol India 2006; 54: 152-156; discussion 156.

10. Ramirez L, Krug A, Nhoung H, et al. Vascular neurologists as directors of Stroke Centers in the United States. Stroke 2015; 46: 2654-2656.

11. Bereczki D and Ajtay A. [Neurology 2009: a survey of Hungarian neurology capacities, their utilization and of neurologists, based on 2009 institutional reports in Hungary]. Ideggyogy Sz 2011; 64: 173-185.

12. Krishnamurthi RV, Feigin VL, Forouzanfar MH, et al. Global and regional burden of first-ever ischaemic and haemorrhagic stroke during 1990-2010: findings from the Global Burden of Disease Study 2010. Lancet Glob Health 2013; 1: e259-e281.

13. Aminoff MJ. Training in neurology. Neurology 2008; 70 : 1912-1915.

14. Bath P, Lees K, Dennis M, et al. Should stroke medicine be a separate subspecialty? BMJ 1997; 315: 1167-1168.

15. Adams HP Jr, Biller J, Juul D and Scheiber S. Certification in vascular neurology: a new subspecialty in the United States. Stroke 2005; 36: 2293-2295.

16. Starke I. Stroke medicine: a new subspecialty. Hosp Med 2004; 65: 369-370.

17. Chen M and Nguyen T. Emerging subspecialties in neurology: endovascular surgical neuroradiology. Neurology 2008; 70: e21-e24.
18. Zakaria A, Provencio JJ and Lopez GA. Emerging subspecialties in neurology: neurocritical care. Neurology 2008; 70: e68-e69.

19. Josephson SA, Engstrom JW and Wachter RM. Neurohospitalists: an emerging model for inpatient neurological care. Ann Neurol 2008; 63: 135-140.

20. Corea F, Gunther A, Kwan J, et al. Educational approach on stroke training in Europe. Clin Exp Hypertens 2006; 28: 433-437.

21. Stern BJ, Lowenstein DH and Schuh LA. Invited article: neurology education research. Neurology 2008; 70: 876-883.

22. Allen SS, Harris IB, Kofron PM, et al. A comparison of knowledge of medical students and practicing primary care physicians about cardiovascular risk assessment and intervention. Prev Med 1992; 21: 436-448.

23. Alberts MJ. Undergraduate and postgraduate medical education for cerebrovascular disease. Stroke 1995; 26 : 1849-1851.

24. Billings-Gagliardi S, Fontneau NM, Wolf MK, Barrett SV, Hademenos G and Mazor KM. Educating the next generation of physicians about stroke: incorporating stroke prevention into the medical school curriculum. Stroke 2001; 32: 2854-2859.

25. Meretoja A and Kantanen A-M. Neurologit tekivät sen taas - auditointien tuloksena entistä parempaa erikoislääkärikoulutusta (Audit Results of Neurology Training in Finland). Finnish Med $J$ 2009; 64: 388-393.

26. Imam I and Akinyemi R. Nigeria. Pract Neurol 2015; 16: 75-77.

27. Kaste M, Palomaki $\mathrm{H}$ and Sarna S. Where and how should elderly stroke patients be treated? A randomized trial. Stroke 1995; 26: 249-253.

28. Smith MA, Liou JI, Frytak JR and Finch MD. 30-day survival and rehospitalization for stroke patients according to physician specialty. Cerebrovasc Dis 2006; 22: 21-26. 